\title{
BMJ Open Demographic profile and pregnancy outcomes of adolescents and older mothers in Saudi Arabia: analysis from Riyadh Mother (RAHMA) and Baby cohort study
}

\author{
Amel A Fayed, ${ }^{1,2}$ Hayfaa Wahabi, ${ }^{3,4}$ Heba Mamdoun, ${ }^{5}$ Reham Kotb, ${ }^{6}$ \\ Samia Esmaeil ${ }^{3}$
}

To cite: Fayed AA,

Wahabi $\mathrm{H}$, Mamdouh $\mathrm{H}$, et al. Demographic profile and pregnancy outcomes of adolescents and older mothers in Saudi Arabia: analysis from Riyadh Mother (RAHMA) and Baby cohort study. BMJ Open 2017;7:e016501. doi:10.1136/ bmjopen-2017-016501

- Prepublication history for this paper is available online. To view these files, please visit the journal online (http://dx.doi. org/10.1136/bmjopen-2017016501).

AAF and HW contributed equally.

Received 23 February 2017

Revised 3 July 2017

Accepted 1 August 2017

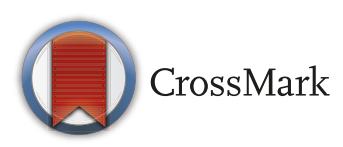

For numbered affiliations see end of article.

Correspondence to

Dr. Amel A Fayed;

fayedam_200@hotmail.com

\section{ABSTRACT}

Objectives To investigate the impact of maternal age on pregnancy outcomes with special emphasis on adolescents and older mothers and to investigate the differences in demographic profile between adolescents and older mothers.

Methods This study is a secondary analysis of pregnancy outcomes of women in Riyadh Mother and Baby cohort study according to maternal age. The study population was grouped according to maternal age into five subgroups; $<20,20-29,30-34,35-39$ and $40+y e a r s$. The age group 20-29 years was considered as a reference group. Investigation of maternal age impact on maternal and neonatal outcomes was conducted with adjustment of confounders using regression models.

Results All mothers were married when conceived with the index pregnancy. Young mothers were less likely to be illiterate, more likely to achieve higher education and be employed compared with mothers $\geq 40$ years. Compared with the reference group, adolescents were more likely to have vaginal delivery (and least likely to deliver by caesarean section (CS); $\mathrm{OR}=0.6,95 \% \mathrm{Cl} 0.4$ to 0.9 , while women $\geq 40$ years, were more likely to deliver by $\mathrm{CS} ; \mathrm{OR}$ $2.9,95 \% \mathrm{Cl} 2.3$ to 3.7. Maternal age was a risk factor for gestational diabetes in women $\geq 40$ years; $0 \mathrm{R} 1.7,95 \% \mathrm{Cl}$ 1.3 to 2.1. Adolescents had increased risk of preterm delivery; $\mathrm{OR} 1.5,95 \% \mathrm{Cl} 1.1$ to 2.1 and women $\geq 40$ years had similar risk; $\mathrm{OR}, 1.3,95 \% \mathrm{Cl} 1.1$ to 1.6 .

Conclusion Adverse pregnancy outcomes show a continuum with the advancement of maternal age. Adolescents mother are more likely to have vaginal delivery; however, they are at increased risk of preterm delivery. Advanced maternal age is associated with increased risk of preterm delivery, gestational diabetes and CS.

\section{INTRODUCTION}

Maternal age is a determining factor for pregnancy outcomes. The impact of maternal age on obstetric and neonatal outcomes was evaluated by several studies from many settings, especially in adolescents and older women.

\section{Strengths and limitations of this study}

- To our knowledge, Riyadh Mother and Baby (RAHMA) is the largest study to address the association between maternal age and adverse pregnancy outcomes among Arab women. As RAHMA has prospectively recruited a large number of pregnant women, it offers accurate data on many maternal and neonatal outcomes in Riyadh and in Saudi Arabia generally. In addition, we were able to adjust for major confounders which make our finding reliable account for the effect of maternal age on the pregnancy outcomes.

- Additional strength of this study is that it recruited 14514 women, which made it possible to divide the study population into subgroups based on the maternal age, with sufficient numbers in each stratum to provide statistical power.

- The current study considered the sociodemographic transitions in the Saudi population which shed more light on their effects on pregnancy outcomes.

- One of the limitation of this study is the number of missing data. However, missing data are clearly reported for each variable and each subgroup showing random distribution with no special pattern. Excluding participants' information with missing data at comparison did not affect the statistical power of the study because of the large sample size.

- Another limitation of this study is the lack of information on history of fertility treatment and assisted reproduction which could have influenced some of the associations between advanced maternal age and pregnancy outcomes. However, it is unlikely that many women have undergone this type of treatment as only $6 \%$ of women 35 years or older have conceived for the first time.

The age of motherhood is underpinned by complex socioeconomic, educational and cultural factors, which differ significantly for different communities. ${ }^{1}$ Furthermore, at the same maternal age group, the pregnancy 
outcome is determined by many factors, most important of which is the availability, access and use of health services. ${ }^{23}$

Advanced maternal age is becoming a feature in many communities around the world. Many women in Europe and most women in USA choose to postpone parenthood, especially among those with tertiary education, to pursue a career of work and better social and financial status. ${ }^{4}$ This choice is driven by the economic crisis, unemployment and job instability. ${ }^{4}$ Postponement of motherhood found support from the social norms and customs of the Western communities which showed increased leniency for voluntary childlessness and non-traditional, outside marriage and living arrangements. ${ }^{4}$ Similarly, in many communities in the Saudi Arabia and other Middle Eastern countries, women continue to have children beyond the age of 35 years, encouraged by the stable financial status of the family, where the husband is the main bread winner and the inclination to have large families.

Conversely, poor economic status at the family and community levels, low education achievement and lack of sex education are recognised factors behind teenage pregnancy in some communities in USA and UK. ${ }^{156}$ Adolescents' pregnancy in many low and middle-income countries is mostly recognised among less educated and low socioeconomic sectors of the community and is associated with poor use of health services, poor maternal nutrition and high rate of maternal, neonatal and infant morbidities and mortality. ${ }^{37}$

Few studies examined the influence of maternal age on the pregnancy outcomes in Saudi Arabia, ${ }^{2}{ }^{9}$ none of which compared the socioeconomic profile of adolescents or older mothers with the reference group. They were consistent in their findings that adolescents' pregnancy is associated with preterm delivery and low birth weight but no other major morbidities when compared with adults' pregnancy. This may be attributed to the socioeconomic profile of pregnant adolescents in Saudi Arabia and the free access and use of maternity care.

Conversely, advanced maternal age ( $\geq 35$ years) was found to be associated with increased risks of maternal and fetal adverse outcomes such as increased rate of caesarean section (CS) delivery, gestational diabetes mellitus (GDM), stillbirth, pre-eclampsia, placenta previa, preterm delivery and increased perinatal mortality. ${ }^{410}$ Moreover, the prevalence of pregestational diabetes (pre-GDM) and hypertension (HTN) are expected to be significantly higher in older mothers, similar to the general population of the same age. ${ }^{11}$ These comorbidities further contributed to the risk of adverse pregnancy outcomes in this age group. ${ }^{11}$

Pregnant Saudi women are eligible for free antenatal care in primary healthcare centres with referral to hospitals for some investigations such as ultrasound scanning or for management of complications. All deliveries take place in hospitals which contributed effectively to improving maternity health as $100 \%$ of deliveries are attended by professional healthcare providers with maternal mortality ratio of less than $13 / 100000 .{ }^{12} 13$

The objectives of this study were:

1. To investigate the impact of maternal age on obstetric and neonatal outcomes of women from Riyadh Mother and Baby (RAHMA) multicentre cohort study, ${ }^{14}$ with special emphasis on adolescents and older mothers;

2. To investigate the differences in the demographic and socioeconomic profile between adolescents and older pregnant women.

\section{METHODS}

This study is a secondary analysis of the maternal and neonatal outcomes of women recruited for RAHMA multicentre cohort study ${ }^{14}$ according to maternal age. RAHMA is a hospital-based prospective cohort study conducted in three hospitals in Riyadh, Saudi Arabia. Recruitment of the cohort commenced in November 2013 and data collection concluded in March 2015. RAHMA study recruited more than 14000 pregnant women and their newborn from three hospitals representing ministry of health, military and university hospitals. All Saudi women were eligible to participate and 14568 were consented. A standardised data collection sheet was used to abstract all obstetric and laboratory data available in women's medical record and a self-administrated questionnaire inquiring about sociodemographic data were used for data collection. ${ }^{14}$

Because RAHMA has systematically recruited a large number of pregnant women, it is expected to provide accurate estimate of the indices of maternal morbidity in Riyadh and to a great extent in Saudi Arabia, bearing in mind that more than $25 \%$ of the Kingdom's population (7.3 million) lives in Riyadh and that all women deliver in hospitals. The detailed methodology of the study has been previously reported. ${ }^{14}$

For this study, the population was grouped according to maternal age into five subgroups; <20, 20-29, 30-34, 35-39 and 40+ years to investigate the effect of maternal age on the pregnancy outcomes. We considered women in age group 20-29 years as reference group.

We compared the four maternal age groups with the reference group with respect to sociodemographic characteristics such as educational level and working status as well as exposure to second-hand smoke exposure (SHS). In addition, maternal characteristics such as body mass index (BMI), associated chronic diseases including obesity, hypertension, pre-GDM and anaemia; and obstetric history such as parity, were compared between the maternal age groups. Conditions associated with the index pregnancy such as GDM, pre-eclampsia and pregnancy induced hypertension were compared.

We investigated the influence of maternal age on the following maternal and neonatal outcomes; gestational age at the time of delivery (preterm, full term and post date), rate of induction of labour, mode of delivery (normal vaginal birth, CS, instrumental delivery), 
maternal admission to intensive care unit (ICU), Apgar score at $5 \mathrm{~min}$, birth weight, macrosomia, admission to neonatal ICU (NICU), rate of stillbirth and congenital anomalies detected by mid-trimester ultrasound scan.

To detect the effect of maternal age on the outcomes of pregnancy, we controlled for maternal characteristics with proven confounding effects on the maternal and neonatal outcomes using multivariate logistic regression models.

\section{Definitions}

For the purpose of the study, we considered the following definitions:

1. Due to the variable cut-off values for the diagnosis of GDM and pre-GDM in the three participating hospitals, we collected the results of the Oral Glucose Tolerance Test between 24 and 34 gestation weeks and the fasting blood glucose $\leq 14$ weeks gestation and then reclassified the participants as non-diabetic, preGDM or GDM based on the following WHO cut-off values ${ }^{15}$ :

Gestational diabetes mellitus should be diagnosed at any time in pregnancy if one or more of the following criteria are met:

- Fasting plasma glucose 5.1-6.9 mmol/L (92$125 \mathrm{mg} / \mathrm{dL}$ );

- One-hour plasma glucose $\geq 10.0 \mathrm{mmol} / \mathrm{L} \quad(180$ $\mathrm{mg} / \mathrm{dL}$ ) following a $75 \mathrm{~g}$ oral glucose load;

- Two-hour plasma glucose $8.5-11.0 \mathrm{mmol} / \mathrm{L} \mathrm{(153-}$ $199 \mathrm{mg} / \mathrm{dL}$ ) following a $75 \mathrm{~g}$ oral glucose load.

Diabetes in pregnancy should be diagnosed if one or more of the following criteria are met:

- Fasting plasma glucose $\geq 7.0 \mathrm{mmol} / \mathrm{L}$ $\mathrm{mg} / \mathrm{dL}$ );

- Two-hour plasma glucose $\geq 11.1 \mathrm{mmol} / \mathrm{L}$ $\mathrm{mg} / \mathrm{dL}$ ) following a $75 \mathrm{~g}$ oral glucose load;

- Random plasma glucose $\geq 11.1 \mathrm{mmol} / \mathrm{L} \quad(200$ $\mathrm{mg} / \mathrm{dL}$ ) in the presence of diabetes symptoms.

2. All participating hospitals follow the same diagnostic criteria for hypertensive disorders of pregnancy which based on the report of the American national working group on high blood pressure in pregnancy. ${ }^{16} \mathrm{In}$ brief, pre-eclampsia is defined as new onset of elevated blood pressure after 20 weeks pregnancy in a previously normotensive woman $(\geq 140 \mathrm{~mm} \mathrm{Hg}$ systolic or $\geq 90 \mathrm{~mm} \mathrm{Hg}$ diastolic on at least 2 occasions 6 hours apart) in addition to proteinuria of at least $1+$ on a urine dipstick or $\geq 300 \mathrm{mg}$ in a 24 -hour urine collection. ${ }^{16}$ Eclampsia is defined as seizures in a pre-eclamptic woman that cannot be attributed to other causes. ${ }^{16}$ Gestational hypertension is defined as new onset of elevated blood pressure $(\geq 140 \mathrm{~mm} \mathrm{Hg}$ systolic or $\geq 90 \mathrm{~mm} \mathrm{Hg}$ diastolic on at least two occasions 6 hours apart) after 20 weeks of gestation in a previously normotensive woman and superimposed pre-eclampsia as new onset of pre-eclampsia after 20 weeks of pregnancy on previously hypertensive woman. ${ }^{16}$
3. Macrosomia is defined as birth weight of $\geq 4.0 \mathrm{~kg}$.

4. Low birth weight (LBW) is defined as birth weight $<2.5 \mathrm{~kg}$.

5. In the three participating hospitals, the pregnancy was considered viable after completion of 24 weeks gestation calculated from the last menstrual period or early ultrasound scan.

6. Postdate pregnancy is defined as pregnancy that continues after 41 completed weeks of gestation. ${ }^{17}$

7. Preterm birth is defined as birth before 37 gestation weeks. It is subclassified to late preterm births (3436 weeks' gestation) and very preterm birth $(<34$ weeks). ${ }^{18}$

8. Maternal intrapregnancy BMI was calculated from maternal weight at 28-30weeks gestation and height with the following cut-off values as suggested by Catalano et al $^{19}$ : normal weight (BMI $<28.4 \mathrm{~kg}$ / $\mathrm{m} 2$ ), overweight (BMI $28.5-32.9 \mathrm{~kg} / \mathrm{m} 2$ ) and obese $(\mathrm{BMI}>33 \mathrm{~kg} / \mathrm{m} 2) .{ }^{19}$

9. Anaemia in pregnancy is defined according to the $\mathrm{WHO}$ as haemoglobin level $<11 \mathrm{~g} / \mathrm{dL}$ and severe anaemia as haemoglobin level $\leq 7 \mathrm{~g} / \mathrm{dL}^{20}$

\section{Statistical analysis}

Descriptive statistics for the criteria of the studied sample used percentages and mean $\pm \mathrm{SD}$ deviation. Comparison of numeric values was conducted by analysis of variance test and the association between the categorical variables was assessed by $\chi^{2}$ test and $p$ value of less than 0.05 was considered statistically significant.

Multivariate logistic regression models were used to adjust comparisons for confounding factors and adjusted OR and 95\% CI are reported. Maternal BMI, parity, pre-GDM and pre-existing HTN were included as confounders in the adjusted analyses based on their wellknown associations with maternal and fetal outcomes. For the purpose of this study, gestational age, birth weight and history of previous CS were added to the confounders in the analyses of CS based on their clinically well-known associations. Adjustment of sociodemographic profile was considered based on the clinical evidence of its confounder effect. The ORs of LBW were estimated among women with singleton full-term delivery only (37-41 weeks). SHS was considered as a confounder in low birth weight and preterm delivery because of its clinical significance. As the reported prevalence of pre-eclampsia and pregnancy-induced hypertension were low, all pregnancy-associated hypertensive disorders were grouped as one outcome in the analysis.

The SPSS V.21.0 statistical package is used for the analyses (IBM SPSS. Statistics for windows).

\section{Ethical approval}

The institutional review boards of the following institutions approved the main cohort study (RAHMA): King Abdullah International Medical Research Centre, approval letter 11/062; King Fahad Medical City Research Centre, approval letter 013-017 and King 
Saud University, approval letter 13-985. The study was conducted according to the principles of Declaration of Helsinki.

\section{RESULTS}

From the RAHMA cohort, 14514 participants were included in this study. The youngest participant in this study was 15 years of age and the eldest was 54 years old.

Nearly half of the participants $(48.0 \%)$ were between 20 and 29 years, while only $2.0 \%$ were below 20 years and $6.4 \%$ were $\geq 40$ years (table 1 ). The majority of the participants were housewives; with comparable proportions between the different age groups (table 1). All participants were married when conceived with the index pregnancy. Only two women $(1.2 \%)$ from those $<20$ years old were illiterate, compared with 51 women $(10.2 \%)$ from the age group $\geq 40$ years. Nearly $45 \%$ of women who were 20-34 years old, achieved university or higher education, compared with only $27.7 \%$ of women $\geq 40$ years of age. Exposure to SHS was reported consistently high among all age groups $(20 \%-23 \%)$ (table 1$)$.

The majority of women $<20$ years $(71.3 \%)$ were primiparous, while only $1.4 \%$ from women $\geq 40$ years delivered for the first time. The proportion of women who have five children or more increased across the age groups to a maximum of $86.6 \%$ in women $\geq 40$ years (table 1 ).

Almost $90 \%$ of the cohort were booked in the respective hospital and attended regular antenatal care with an increased trend across the age groups (table 1). The prevalence of anaemia in cohort was $32.8 \%$ and that of severe anaemia is $2.1 \%$, with the least prevalence among adolescents (table 1 ).

The mean BMI of the participants showed an increased trend through the age groups with the lowest among women $<20$ years and the highest at age group $\geq 40$ years (table 1). In addition, the prevalence of obesity during pregnancy $\left(\mathrm{BMI}>33 \mathrm{~kg} / \mathrm{m}^{2}\right)$ was high among the whole cohort, showing a trend of increasing proportions across age groups from as low as $22.2 \%$ among mothers $<20$ years to as high as $57.6 \%$ among mother $\geq 40$ years.

The rate of associated medical disorders during pregnancy was highest among women aged $\geq 40$ years. The prevalence of pre-GDM of the reference age group (20-29 years) was $2.4 \%$, which is comparable to the prevalence of those $<20$ years $(1.7 \%)$. However, the prevalence of pre-GDM increases exponentially among mother $\geq 40$ years to reach $12.7 \%$. In addition, a gradient of increased prevalence of pre-GDM is evident with the increased maternal age (figure 1).

Similarly, the highest prevalence of hypertensive disorders during pregnancy was noted among women $\geq 40$ years $(9.7 \%)$, which was more than threefold the prevalence in the reference group $(2.8 \%)$ with an increased prevalence across the age groups. A smaller increase in the prevalence of all hypertensive disorders $(3.4 \%)$ and pre-eclampsia $(2.4 \%)$ was noticed in women $<20$ years compared with the reference group (table 1 ).
High prevalence of GDM was detected in this cohort; with the lowest prevalence reported in women $<20$ years $(17.7 \%)$ and the highest was in women $\geq 40$ years $(33.9 \%)$ (table 2 and figure 2). Although the effect of maternal age as a risk factor for GDM was attenuated for all age groups when adjustment for maternal BMI and parity (table 3), it persisted as a risk factor for group 30-34, 35-30 and $40+$ years with the highest risk for group 5; OR 1.7, 95\% CI 1.3 to 2.1 .

There were no significant differences between the groups in the prevalence of postdate pregnancy, IOL and maternal admission to ICU or structural abnormalities detected by mid-trimester ultrasound scan (table 2).

The risk of premature delivery, macrosomia, neonatal admission to NICU, stillbirth, CS delivery and GDM increased with the increase in maternal age (table 2, figure 2). However, after adjustment for confounders, maternal age was not a risk factor for any neonatal complication other than prematurity (table 3 ). Compared with the reference group, women $<20$ years have increased risk of preterm delivery; OR $1.5,95 \%$ CI 1.1 to 2.1 . In addition, women $\geq 40$ years had similar risk; OR, $1.3,95 \%$ CI 1.1 to 1.6 .

Compared with the reference group, mothers women $<20$ years were more likely to have vaginal delivery (84.4\%), $\mathrm{p}<0.01$ (table 2 ), and least likely to deliver by CS, OR $0.6,95 \%$ CI 0.4 to $0.9, \mathrm{p}<0.01$ (table 3 ). Moreover, women $\geq 40$ years were more likely to deliver by CS $(33.8 \%), \mathrm{p}<0.01$, and least likely to have vaginal delivery (64.6\%), $\mathrm{p}<0.01$ (table 2). After adjustment of confounders, maternal age persisted as risk factor for CS delivery in age groups $30-39$ years and increased the odds for such delivery by more than twofold in women $\geq 40$ years, OR 2.9, 95\% CI 2.3 to 3.7 (table 3 ).

After adjustment of confounders, maternal age was no longer a risk factor for hypertensive disorders in women $<20$ years; however, it increased the odds by more than threefold, OR $3.3,95 \%$ CI 2.1 to 5.3 for mothers $\geq 40$ years (table 3 ).

\section{DISCUSSION}

The findings of this study concurred with previous reports that adolescents' pregnancy is associated with increased risk of preterm delivery but reduced risk of CS delivery.

It confirmed that older women had nearly fourfold increased risk for CS compared with the reference group, in addition to increased risk of preterm birth, GDM and pregnancy-associated hypertensive disorders. Furthermore, older mothers are more likely to suffer from chronic diseases and their complications in pregnancy, including obesity, anaemia and pre-GDM.

A trend of changing in the sociodemographic characteristics in the Saudi female population is noticeable in the present cohort. There was significant improvement in the educational and the employment status across maternal age groups. The majority of mothers in this cohort was literate; however, there is marked difference 


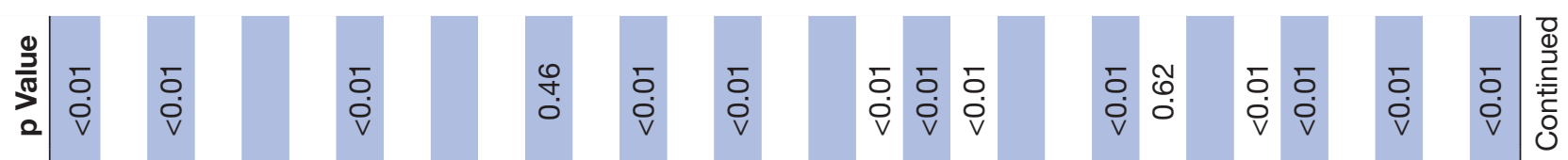

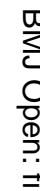

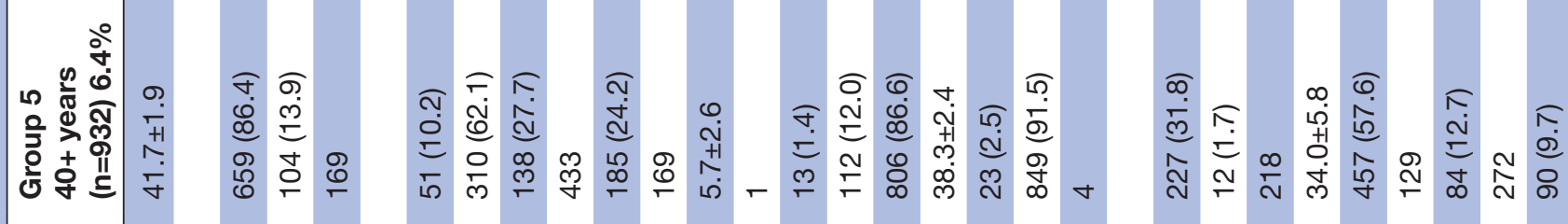

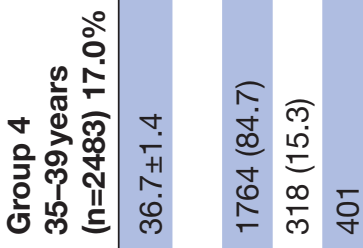

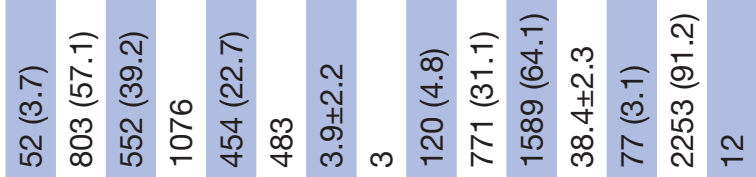

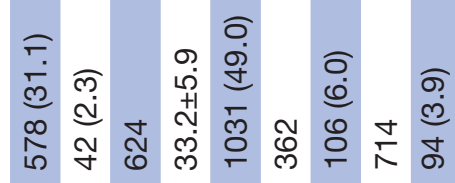

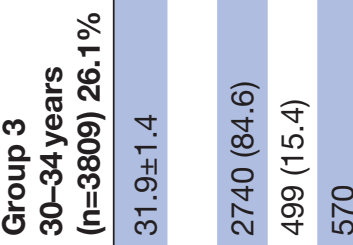

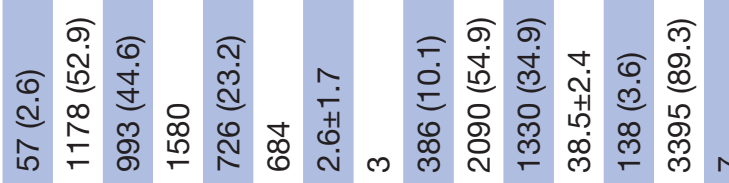

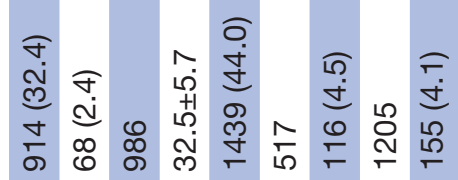

ว

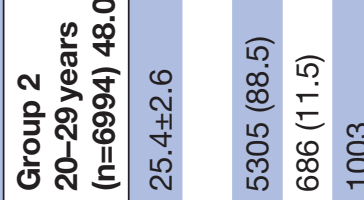

के क.

จิ์

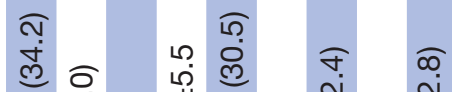

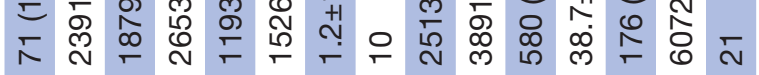

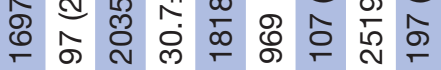

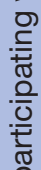

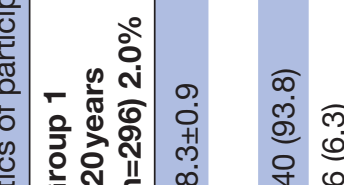

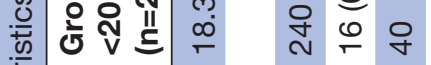

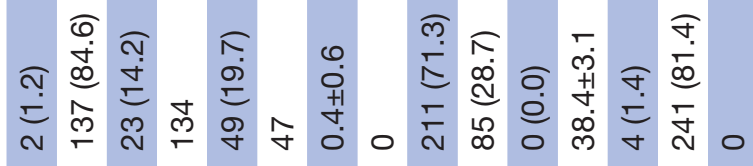

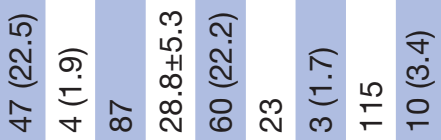

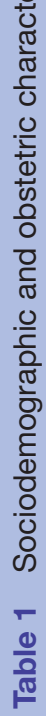

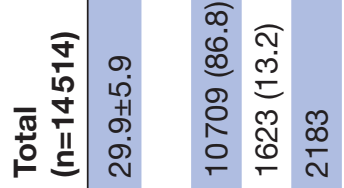

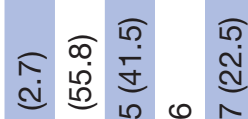

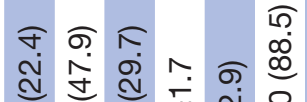

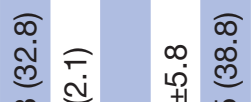

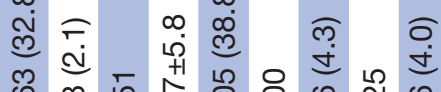

m)

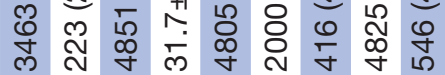

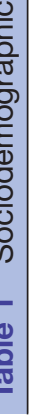

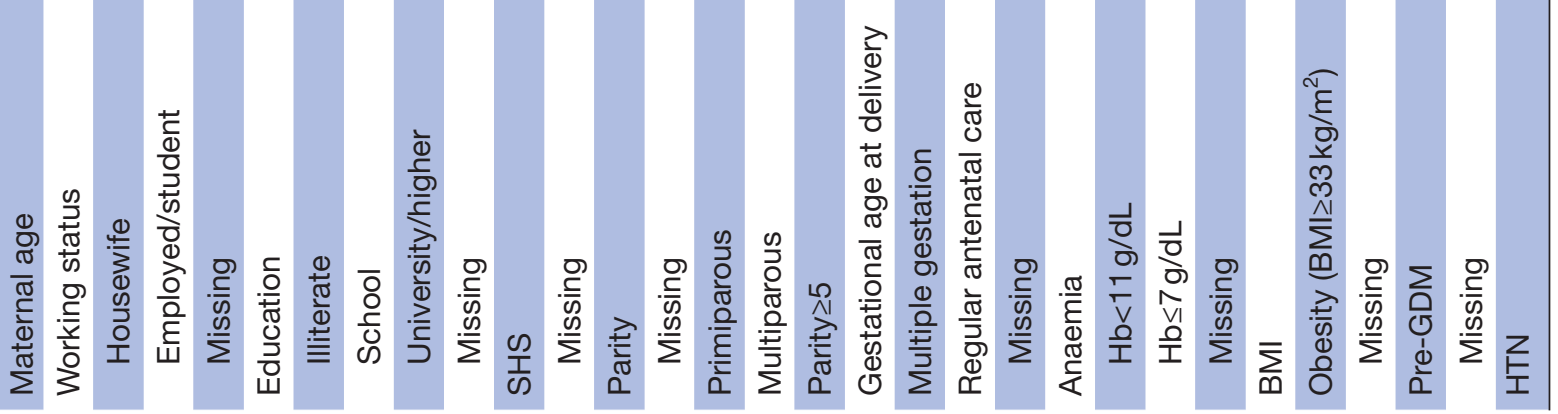




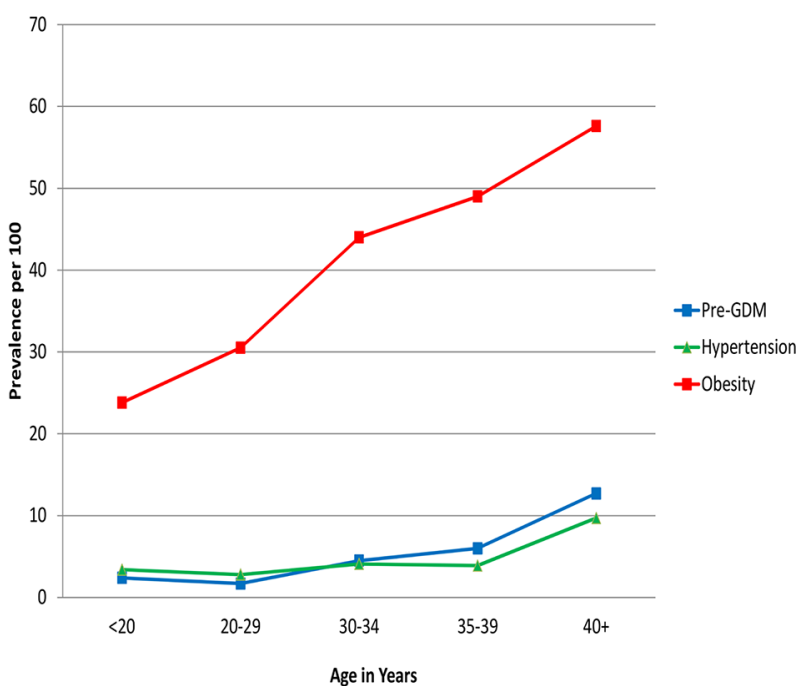

Figure 1 Prevalence of pregestational chronic diseases in the study population according to maternal age. Pre-GDM, pregestational diabetes mellitus.

between adolescents' literacy level, where only $1.2 \%$ were illiterate compared with $10 \%$ illiteracy rate among mothers 40 years or more. These findings confirmed previous reports by the WHO on Saudi women education and employment where Saudi females' employment rates have risen by $85 \%$ from the year 2009 to 2013, and the literacy rates that increased from $79.7 \%$ in 2004 to $85.0 \%$ in 2010. ${ }^{2122}$ This improvement in the sociodemographic indicators has reflected positively on all pregnancy outcomes including the maternal mortality ratio which declined from 46/100 000 in 1990 to 23/100 000 in 2000 and further to $12 / 100000$ in $2015 .^{23}$

The rate of adolescent pregnancy in this study was 20 per 1000 , which is lower than the 60 per 1000 incidence reported during 1999 from Riyadh. ${ }^{24}$ Data from World Bank about adolescent fertility reported a decline in rate in the Saudi Arabia from 124 per 1000 in 1960 to 9 per 1000 in $2014 .{ }^{25}$ This decline of teenage pregnancy can be explained by improvement in educational level and the socioeconomic status of women as part of the Saudi community.

The favourable outcomes of adolescents' pregnancy shown by the current study, apart from increase prevalence of preterm birth, can be attributed to the favourable socioeconomic conditions and family support, as all women were married, in addition to the improved medical care for the young pregnant women. Unlike adolescents' pregnancy in other communities, ${ }^{72627}$ teenage mothers in this study had high rate of attending regular antenatal care and have the lowest rate of anaemia among the study population (table 1). Our findings are consistent with previous reports from Saudi Arabia on the outcomes of adolescents pregnancy. ${ }^{29}$

In this cohort, the rate of pregnancy in women 35 years or older is $23 \%$ which is higher than rates reported from other parts of Saudi Arabia ${ }^{9}$ but similar to figures reported from other parts of the world such as Finland ${ }^{28}$ and the 
Table 2 Maternal and neonatal outcomes of the cohort according to maternal age

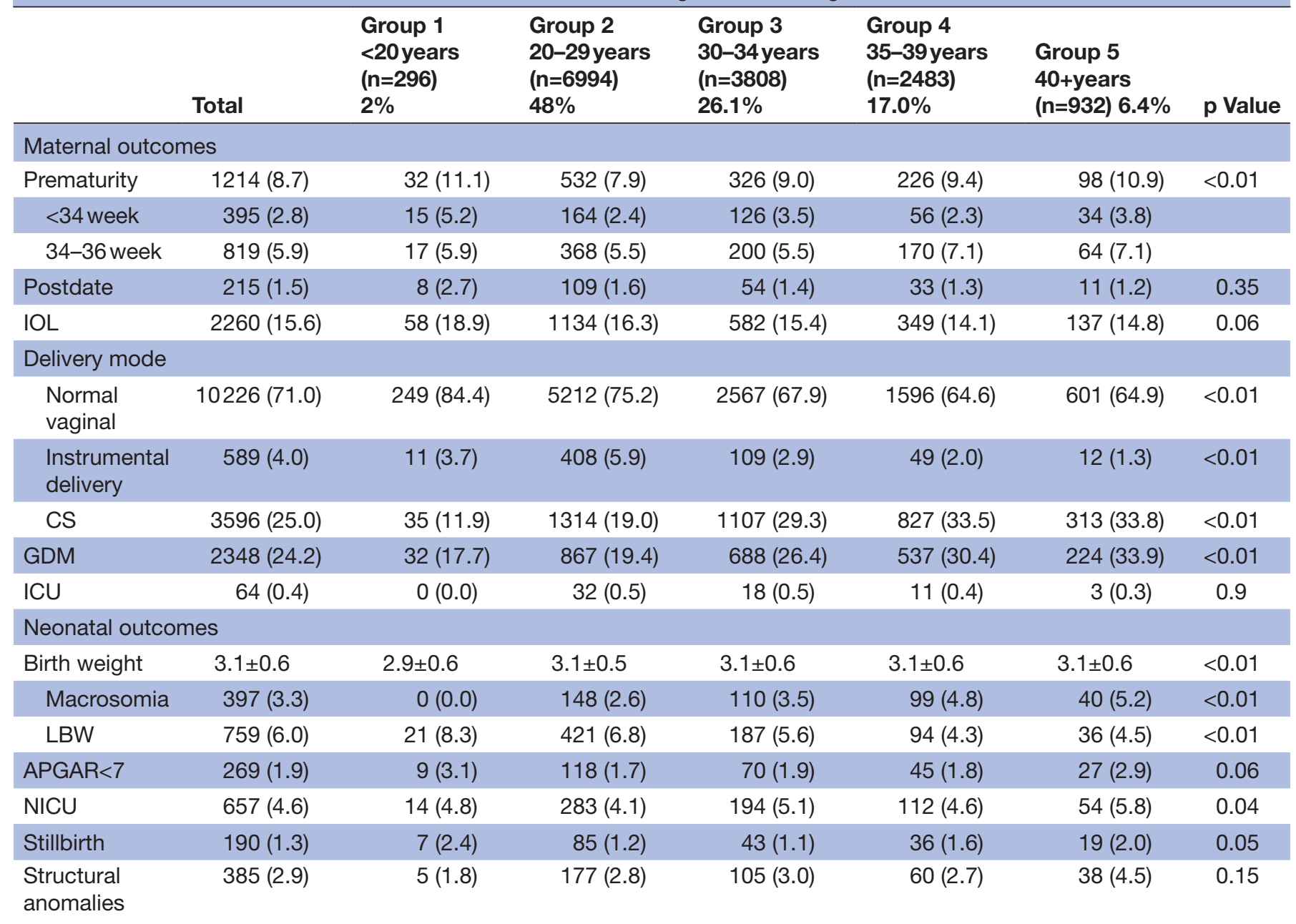

CS, caesarean section; GDM, gestational diabetes mellitus; ICU, intensive care unit; IOL, Induction of labour; LBW, low birth weight; NICU, neonatal ICU.

USA. $^{29}$ The demographic characteristics of women 35 years or older indicate that only $6 \%$ of this group had conceived for the first time and that most of them have five or more children. Women 40 years or more have the highest illiteracy rate in the cohort and the least higher education rate. These findings indicate that pregnancy in advanced maternal age in the Saudi community is not due to postponement of motherhood but rather due to continuing pregnancy and childbirth beyond the age of 35 years. Considering the education and work status of this group, one can conclude that pregnancy at this age group was motivated by reasons other than pursuing a career of work or higher education.

In this study, many adverse pregnancy outcomes showed a continuum of increased prevalence with the advancement of maternal age. These results concur with the findings of other investigators ${ }^{41030}$ and with similar reports from Saudi Arabia. ${ }^{9}$ The association between advanced maternal age and adverse pregnancy outcomes has been explained in part by the increased prevalence of pregestational chronic diseases such as diabetes, hypertension and obesity, ${ }^{11}$ in addition to the ageing process, which affects the reproductive system similar to other systems in the human body.

The impact of maternal age as a risk factor for adverse pregnancy outcome was attenuated considerably when we considered chronic disease as risk factors for adverse maternal and neonatal outcomes (table 3). However, similar to previous reports, advanced maternal age remained a risk factor for preterm delivery, GDM, pregnancy associated hypertension and CS delivery. ${ }^{102931}$

Our results showed that preterm delivery is more prevalent in adolescents and those above 40 years demonstrating a U-shape distribution (figure 2). This concurred with previous reports ${ }^{1032}$ which confirmed that maternal age is a risk factor for premature birth. The increased risk of preterm delivery among teenagers has been explained by the low socioeconomic conditions of the teenage mothers and increased nutritional demands of pregnancy. ${ }^{33}$ However, physical immaturity including short cervix and small uterine volume ${ }^{34}$ may be a better explanation to high prevalence of preterm delivery in our cohort due to the stable socioeconomic condition observed in this group. Similar to previous reports, ${ }^{35} 36$ 
maternal age

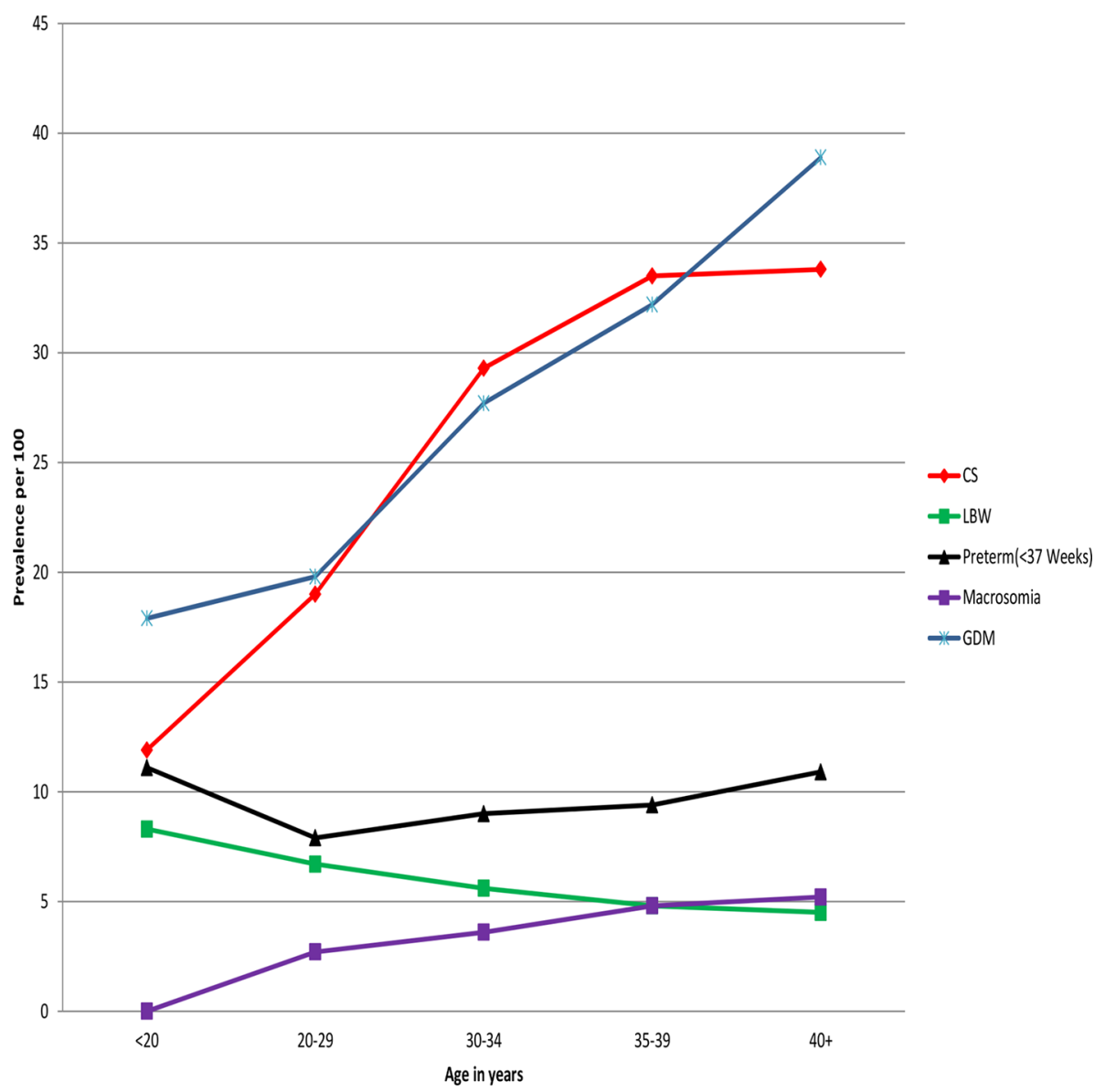

Figure 2 Prevalence of maternal and neonatal outcomes in the study population according to maternal age. CS, caesarian section; GDM, gestational diabetes mellitus; LBW, low birth weight.

the preterm birth among older women may be attributed to iatrogenic preterm delivery indicated by the pregestational comorbidities and the associated complications.

In the current study, the risk of developing GDM increased progressively with the increase in maternal age to a stage where every third woman at the age of $\geq 40$ developed GDM (figure 2). This increased risk could be explained by the increase in insulin resistance and impairment in the function of $\beta$ cells of the pancreas as the maternal age advances and BMI increases. ${ }^{37}$

In spite of the low prevalence of all pregnancy-associated HTN in this study, the prevalence has progressively increased with advancing maternal age and the risk of developing HTN was nearly threefold among the eldest group compared with the reference group. Pre-eclampsia rate showed two peaks; one in adolescents and a lesser peak in women over 40 years; however, this U-shape prevalence did not persist after adjustment of confounders. These findings suggest that although advanced age might not be the only responsible risk factor for all hypertensive disorders of pregnancy, its effects cannot be ignored. These findings are in accordance with other reports. ${ }^{10} 30$

Although young mothers were less likely to be delivered by CS, the risk for operative delivery was increased by almost threefold for women aged 40 years and above (table 3, figure 2). These results are consistent with previous reports ${ }^{1029}$ and may be explained by the optimum health status of young mothers with low parity and with no prior caesarean deliveries in contrast to the older age women with high parity and pregestational chronic diseases, which may indicate CS delivery.

We noticed a trend of a decreased risk of low birth weight as maternal age increases (table 3) even after adjustment of confounders especially in the age group 35-39 years. Different patterns of associations between maternal age and low birth weight were reported by investigators. ${ }^{38}$ Most are related to race/ethnicity, maternal weight gain and nutritional habits of young and older mothers. ${ }^{40}$ Similar factors may explain our results especially that we have not investigated the nutritional habits of the participants nor the maternal weight gain in this study.

Although maternal age was not a risk factor for the other maternal and neonatal adverse outcomes shown in table 2, these adverse outcomes show the same pattern of continuum through maternal age. Other risk factors which are associated with adverse pregnancy outcomes including obesity, pre-GDM and high parity are prevalent in the cohort and increased in frequency with the increase in maternal age (table 1). 
Table 3 The crude and adjusted OR for maternal and neonatal outcomes

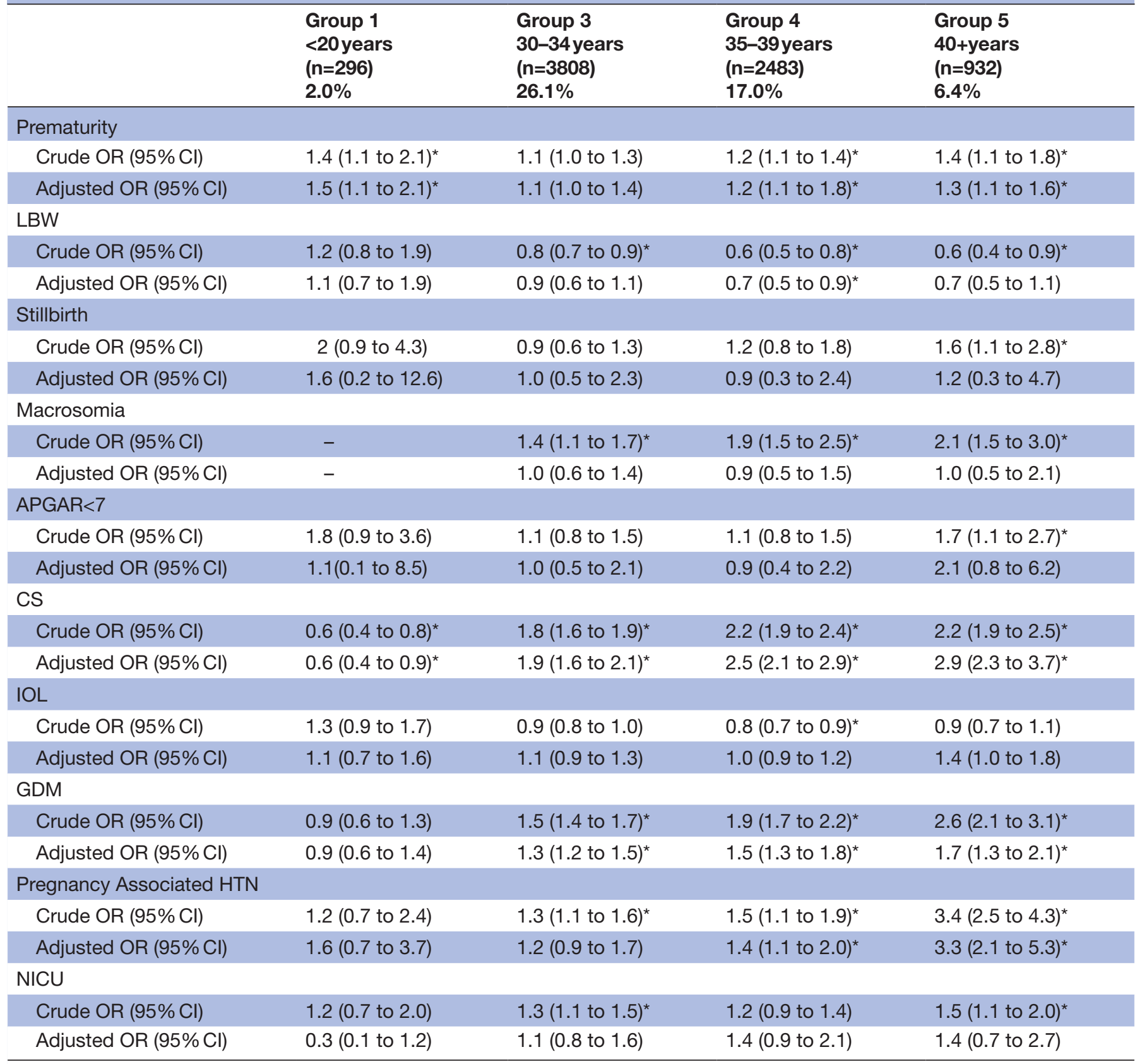

${ }^{*} \mathrm{p}$ Value $<0.05$.

CS: adjusted for BMI, parity, pregnancy-associated HTN, all DM, birth weight, gestational age, history of previous CS, education and employment. IOL: adjusted for BMI, parity, pregnancy-associated HTN, DM, birth weight and gestational age. LBW: (full-term singleton): adjusted for BMI, parity, gestational age, SHS, HTN, all diabetes. Macrosomia: adjusted for BMI, parity, gestational age, HTN, diabetes, education and employment. Preterm: adjusted for parity, HTN, BMI, SHS, DM, education and employment. Stillbirth: adjusted for parity, HTN, BMI, SHS, DM, education and employment. APGAR: $<7$ adjusted for BMI, parity, gestational age, SHS, HTN, diabetes. GDM: adjusted for parity, BMI. Pregnancy-associated (pregnancy-induced and pre-eclampsia) HTN: adjusted for parity, BMI, GDM, preexisting HTN. NICU: adjusted for parity, gestational age, birth weight, HTN, DM.BMI, body mass index; CS, caesarean section; GDM, gestational diabetes mellitus; HTN, hypertension; ICU, intensive care unit; IOL, induction of labour; LBW, low birth weight; NICU, neonatal intensive care unit.

The prevalence of pregestational chronic diseases in this cohort was exceptionally high in advanced maternal age, especially for diabetes and obesity, compared with reports from Australia and Israel. ${ }^{36}$ Previous studies reported significant increase in the prevalence of both overweight and obesity with advancement of maternal age among Saudi women. ${ }^{42}$ The rates of obesity and overweight in pregnancy were high among all age groups with almost $60 \%$ of the women in the advanced age groups reported to be obese. Maternal obesity is associated with increased risk of GDM, macrosomia, stillbirth and CS delivery. ${ }^{434}$

The results of the current study showed that the prevalence of pre-GDM gradually increased with advancing maternal age until it reached near that of the general 
Saudi population of $24 \%^{45}$ in the eldest age group (figure 1). Pre-GDM is associated with many adverse maternal and neonatal outcomes including CS delivery, macrosomia, congenital malformations, stillbirth and preterm delivery. ${ }^{46-48}$

Almost one-third of the participants of this study were grandmultiparae. In addition, nearly $90 \%$ of women 40 years or above were of high parity. Studies from Saudi Arabia, which investigated the effects of high parity on the pregnancy outcomes, showed strong association between grandmultiparity and adverse pregnancy outcomes independent of maternal age. ${ }^{49} 50$ Grandmultiparity was found to be associated with malpresentation, abnormal placentation, antepartum haemorrhage, CS delivery, anaemia and increased perinatal mortality. ${ }^{50}$

\section{CONCLUSION}

Adverse pregnancy outcomes show a continuum with the advancement of maternal age. Adolescents mother are more likely to have vaginal delivery and less likely to be delivered by CS, compared with adults. However, they are at increased risk of preterm delivery. Advanced maternal age is associated with increased risk of preterm delivery, GDM and CS delivery. Pregestational chronic diseases, among Saudi mothers, are major risk factors for adverse pregnancy outcomes especially with the advancement of maternal age.

\section{Author affiliations}

${ }^{1}$ Department of Biostatistics, High Institute of Public Health, Alexandria University, Alexandria, Egypt

${ }^{2}$ College of Medicine, Clinical department, Princess Nourah Bint Abdulrahman University, Riyadh, Riyadh, Saudi Arabia

${ }^{3}$ Chair of Evidence Based Health Care and Knowledge Translation, College of Medicine, King Saud University, Riyadh, Saudi Arabia

${ }^{4}$ Department of Community and Family Medicine, King Saud University, Riyadh, Saudi Arabia

${ }^{5}$ Department of Family Health, High Institute of Public Health, Alexandria University, Alexandria, Egypt

${ }^{6}$ Primary Health Care, High Institute of Public Health, Alexandria University, Alexandria, Egypt

Acknowledgements We extend our thanks to King Saud University, Deanship of Scientific Research, Research Chairs for funding this project.

Contributors AF and HW conceived and designed the study, analysed the data and equally contributed and reviewed drafts of the manuscript. HM and RK took part in cowriting of the manuscript and interpretation of data. SE participated in design and implementation, analysis and interpretation of data. All authors revised and approved the final draft.

Funding The project was financially supported by King Saud University, Deanship of Scientific Research, Research Chairs.

Competing interests None declared.

Patient consent Obtained.

Ethics approval King Abdullah International Medical Research Centre, approval letter 11/062; King Fahad Medical City Research Centre, approval letter 013-017 and King Saud University, approval letter 13-985.

Provenance and peer review Not commissioned; externally peer reviewed.

Data sharing statement We confirm that any interested researcher can obtain a minimal data set after contacting one of the main authors, AF or HW. AF can be contacted at fayedam_200@hotmail.com and HW can be contacted at umlena@ yahoo.com.
Open Access This is an Open Access article distributed in accordance with the Creative Commons Attribution Non Commercial (CC BY-NC 4.0) license, which permits others to distribute, remix, adapt, build upon this work non-commercially, and license their derivative works on different terms, provided the original work is properly cited and the use is non-commercial. See: http://creativecommons.org/ licenses/by-nc/4.0/

(c) Article author(s) (or their employer(s) unless otherwise stated in the text of the article) 2017. All rights reserved. No commercial use is permitted unless otherwise expressly granted.

\section{REFERENCES}

1. McCall SJ, Bhattacharya S, Okpo E, et al. Evaluating the social determinants of teenage pregnancy: a temporal analysis using a UK obstetric database from 1950 to 2010. J Epidemiol Community Health 2015;69:49-54

2. Al-Kadri HM, Madkhali A, Al-Kadi MT, et al. Tertiary care availability and adolescent pregnancy characteristics in Saudi Arabia. Int $J$ Womens Health 2014;6:359-66.

3. Singh PK, Rai RK, Alagarajan M, et al. Determinants of maternity care services utilization among married adolescents in rural India PLoS One 2012;7:e31666.

4. Schmidt L, Sobotka T, Bentzen JG, et al. Demographic and medical consequences of the postponement of parenthood. Hum Reprod Update 2012;18:29-43.

5. Penman-Aguilar A, Carter M, Snead MC, et al. Socioeconomic disadvantage as a social determinant of teen childbearing in the U.S. Public Health Rep 2013;128(Suppl 1):5-22.

6. Dehlendorf C, Marchi K, Vittinghoff E, et al. Sociocultural determinants of teenage childbearing among Latinas in California. Matern Child Health J 2010;14:194-201.

7. Shahabuddin AS, Delvaux T, Abouchadi S, et al. Utilization of maternal health services among adolescent women in Bangladesh: A scoping review of the literature. Trop Med Int Health 2015;20:822-9.

8. Balaha MH, Amr MA, El-Gilany AA, et al. Obstetric and psychiatric outcomes in a sample of Saudi teen-aged mothers. TAF Preventive Medicine Bulletin 2009;8:285-90.

9. El-Gilany AA, Hammad S. Obstetric outcomes of teenagers and older mothers: experience from Saudi Arabia. Int $\mathrm{J}$ Collab Res Intern Med Public Health 2012;4:901-9.

10. Blomberg M, Birch Tyrberg R, Kjølhede P. Impact of maternal age on obstetric and neonatal outcome with emphasis on primiparous adolescents and older women: a Swedish Medical Birth Register Study. BMJ Open 2014;4:e005840.

11. Carolan M. Maternal age $\geq 45$ years and maternal and perinatal outcomes: a review of the evidence. Midwifery 2013;29:479-89.

12. Al-Yousuf M, Akerele TM, Al-Mazrou YY. Organization of the Saudi health system. East Mediterr Health J 2002;8:645-53.

13. Habib F, Hanafi MI, El-Sagheer A. Antenatal care in primary health care centres in Medina, Saudi Arabia, 2009: a cross-sectional study. East Mediterr Health J 2011;17:196-202.

14. Wahabi H, Fayed A, Esmaeil S, et al. Riyadh Mother and Baby Multicenter Cohort Study: the cohort profile. PLoS One 2016;11:e0150297.

15. World Health Organization. Diagnostic criteria and classification of hyperglycaemia first detected in pregnancy. Diabetes Res Clin Pract 2014;103:341-63.

16. Working Group on Research on Hypertension in Pregnancy. Report of the National High Blood Pressure Education Program Working Group on High Blood Pressure in Pregnancy. Am J Obstet Gynecol 2000;183:S1-22.

17. Delaney M, Roggensack A, Leduc DC, et al. Guidelines for the management of pregnancy at $41+0$ to $42+0$ weeks. $J$ Obstet Gynaecol Can 2008;30:800-23.

18. Shapiro-Mendoza CK, Lackritz EM. Epidemiology of late and moderate preterm birth. Semin Fetal Neonatal Med 2012;17:120-5.

19. Catalano PM, Mclntyre HD, Cruickshank JK, et al. The hyperglycemia and adverse pregnancy outcome study: associations of GDM and obesity with pregnancy outcomes. Diabetes Care 2012;35:780-6.

20. World Health Organization. Haemoglobin concentrations for the diagnosis of anaemia and assessment of severity. Vitamin and mineral nutrition information system. Geneva, Switzerland 2011.

21. WHO. Country cooperation strategy for WHO and Saudi Arabia 2012-2016, 2012. http://www.who.int/countryfocus/cooperation strategy/ccs_sau_en.pdf

22. Saudi Ministry of Labor. Data \& Statistics. The annual statistical book 2013. 2013 www.moh.gov.sa/en/Ministry/Statistics/book/ 
23. WHO. Maternal Mortality Estimation, Saudi Arabia 1990-2015Ref Type: Online Source. 2015 http://www.who.int/gho/maternal_health/ countries/sau.pdf

24. Mesleh RA, Al-Aql AS, Kurdi AM, et al. Teenage pregnancy. Saudi Med J 2001;22:864-7.

25. World Bank TW. Adolescent fertility rate (births per 1,000 women ages 15-19). 2017 http://data.worldbank.org/indicator/SP.ADO.TFRT

26. Kawakita T, Wilson K, Grantz KL, et al. Adverse maternal and neonatal outcomes in adolescent pregnancy. J Pediatr Adolesc Gynecol 2016;29:130-6.

27. Pinho-Pompeu M, Surita FG, Pastore DA, et al. Pinto E Silva JL. Anemia in pregnant adolescents: impact of treatment on perinata outcomes. J Matern Fetal Neonatal Med 2016:1-5.

28. Stakes Parturients, births and newborns 2007. Statistical summary 30/2008. 2008 http: // www.stakes.fi/tilastot/tilastotiedotteet/2008/ tt30_08.pdf.

29. Cleary-Goldman J, Malone FD, Vidaver J, et al. Impact of maternal age on obstetric outcome. Obstet Gynecol 2005;105:983-90.

30. Matsuda Y, Kawamichi Y, Hayashi K, et al. Impact of maternal age on the incidence of obstetrical complications in Japan. J Obstet Gynaecol Res 2011;37:1409-14.

31. Oakley L, Penn N, Pipi M, et al. Risk of adverse obstetric and neonatal outcomes by maternal age: quantifying individual and population level risk using routine UK maternity data. PLoS One 2016;11:e0164462.

32. Demirci O, Yilmaz E, Tosun O, et al. Effect of young maternal age on obstetric and perinatal outcomes: results from the tertiary center in Turkey. Balkan Med J 2016;33:344-9.

33. Ganchimeg T, Ota E, Morisaki N, et al. Pregnancy and childbirth outcomes among adolescent mothers: a World Health Organization multicountry study. BJOG 2014;121(Suppl 1):40-8

34. Stevens-Simon C, Beach RK, McGregor JA. Does incomplete growth and development predispose teenagers to preterm delivery? A template for research. J Perinatol 2002;22:315-23.

35. Jacobsson B, Ladfors L, Milsom I. Advanced maternal age and adverse perinatal outcome. Obstet Gynecol 2004;104:727-33.

36. Simchen MJ, Yinon Y, Moran O, et al. Pregnancy outcome after age 50. Obstet Gynecol 2006;108:1084-8

37. Makino N, Shirahata N, Honda T, et al. Pancreatic hyperechogenicity associated with hypoadiponectinemia and insulin resistance: a Japanese population study. World J Hepatol 2016;8:1452-8.
38. Dennis JA, Mollborn S. Young maternal age and low birth weight risk: an exploration of racial/ethnic disparities in the birth outcomes of mothers in the United States. Soc Sci J 2013:50:625-34.

39. Lee KS, Ferguson RM, Corpuz M, et al. Maternal age and incidence of low birth weight at term: a population study. Am J Obstet Gynecol 1988;158:84-9

40. Tierney-Gumaer R, Reifsnider E. Risk factors for low birth weight infants of Hispanic, African American, and White women in Bexar County, Texas. Public Health Nurs 2008;25:390-400.

41. Carolan MC, Davey MA, Biro M, et al. Very advanced maternal age and morbidity in Victoria, Australia: a population based study. BMC Pregnancy Childbirth 2013;13:80.

42. Al-Malki JS, Al-Jaser MH, Warsy AS. Overweight and obesity in Saudi females of childbearing age. Int J Obes Relat Metab Disord 2003;27:134-9.

43. Sebire NJ, Jolly M, Harris JP, et al. Maternal obesity and pregnancy outcome: a study of 287,213 pregnancies in London. Int J Obes Relat Metab Disord 2001;25:1175-82.

44. Moussa HN, Alrais MA, Leon MG, et al. Obesity epidemic: impact from preconception to postpartum. Future Sci OA 2016;2:FSO137.

45. Al-Rubeaan K, Al-Manaa HA, Khoja TA, et al. Epidemiology of abnormal glucose metabolism in a country facing its epidemic: SAUDI-DM study. J Diabetes 2015;7:622-32.

46. Wahabi HA, Esmaeil SA, Fayed A, et al. Pre-existing diabetes mellitus and adverse pregnancy outcomes. BMC Res Notes 2012;5:496.

47. Macintosh MC, Fleming KM, Bailey JA, et al. Perinatal mortality and congenital anomalies in babies of women with type 1 or type 2 diabetes in England, Wales, and Northern Ireland: population based study. BMJ 2006;333:177.

48. Wahabi $\mathrm{H}$, Fayed $\mathrm{A}$, Esmaeil $\mathrm{S}$, et al. Prevalence and complications of pregestational and gestational diabetes in Saudi women: analysis from Riyadh Mother and Baby cohort study (RAHMA). Biomed Res Int 2017;2017:6878263.

49. Al Rowaily MA, Alsalem FA, Abolfotouh MA. Cesarean section in a high-parity community in Saudi Arabia: clinical indications and obstetric outcomes. BMC Pregnancy Childbirth 2014;14:92.

50. Jf A. Grandmultiparity: a potential risk factor for adverse pregnancy outcomes. J Reprod Med 2012;57:53-7. 